\title{
Red Mud-Based Polyaluminum Ferric Chloride Flocculant: Preparation, Characterization and Flocculation Performance
}

\section{Yong Cheng}

Chongqing University

Longjun Xu ( $\nabla$ xulj@cqu.edu.cn )

Chongqing University https://orcid.org/0000-0001-7469-9721

Chenglun Liu

Chongqing University

Zao Jiang

Chongqing University

Qiyuan Zhang

Chongqing University

Yi Zou

Chongqing University

Yan Chen

Chongqing University

Jingya Li

Chongqing University

Xiuzhu Liu

Chongqing University

\section{Research Article}

Keywords: Red mud, Polyaluminum iron chloride flocculant, Landfill leachate, Flocculation performance, COD, mechanism

Posted Date: February 9th, 2021

DOI: https://doi.org/10.21203/rs.3.rs-159842/v1

License: (c) (1) This work is licensed under a Creative Commons Attribution 4.0 International License.

Read Full License 


\section{Abstract}

In this work, red mud was used as raw material to extract Al and Fe with hydrochloric acid. The highefficiency polyaluminum iron chloride (PAFC) flocculant was prepared via adjusting the $\mathrm{pH}$ of the leaching solution, the molar ratio of aluminum and iron, and the polymerization temperature. The effect of synthesis and flocculation conditions on the flocculation performance of aged landfill leachate was investigated. The results confirmed that the PAFC prepared at the polymerization $\mathrm{pH}$ of 2.5 , the $\mathrm{Al} / \mathrm{Fe}$ molar ratio of 8 , and the polymerization temperature of $70^{\circ} \mathrm{C}$ had the optimum flocculation effect. The flocculation consequences of PAFC and commercial polyaluminum iron chloride flocculant (CPAFC) under different flocculation conditions were compared. The chemical oxygen demand (COD), UV 254 , chroma and settlement height of PAFC at flocculant concentration of $60 \mathrm{~g} / \mathrm{L}$ and solution pH of 6 were $72.2 \%, 79.2 \%, 82.9 \%$ and $9.5 \mathrm{~cm}$ (within $90 \mathrm{~min}$ ), respectively. PAFC has excellent flocculation performance and can be used as a simple, potentially low-cost wastewater treatment agent in industrial applications.

\section{Introduction}

Red mud (RM) is a strong alkaline solid waste discharged during the production of alumina by the Bayer process (Alam et al. 2019). At present, about 1.0-1.5 $\mathrm{t}$ of RM is generated from $1 \mathrm{t}$ of alumina production, which is mainly related to the characteristics and production process of bauxite (Khairul et al. 2019, Samal et al. 2013). The world's current RM stockpiles have exceeded 4 billion tons, and it is increasing at a rate of 120 million t/a. China's RM stockpiles are as high as 600 million tons, accounting for $16 \%$ of the global RM stockpiles. Surprisingly, they are still growing at a rate of 70 million tons per year (Xue et al. 2016a). The common disposal methods of RM include wet drainage (solid mass of 15-30 wt\%) and dry damming (solid mass of 50-56 wt\%) (Power et al. 2011). As the world's largest alumina and RM manufacturer, China mainly adopts wet drainage (Liu et al. 2014). The accumulation of RM has caused a large number of environmental safety problems, such as land occupation, air pollution, groundwater pollution, and dam failure (Gelencser et al. 2011, Kovacs et al. 2013, Mayes et al. 2016, Winkler et al. 2018 , Xue et al. 2016b). These issues are closely related to the strong alkalinity and high salinity of RM (Ding et al. 2020). Therefore, considering the lack of mineral resources and environmental protection, the recovery of valuable resources in RM has become increasingly important. The rational use of RM can not only solve environmental pollution, but also alleviate resource shortages.

Landfill leachate refers to the sewage produced in the landfill owing to anaerobic fermentation, organic fermentation, subsequent washing, and soaking of groundwater (Baderna et al. 2019). In modern production and life, the average daily amount of garbage processed has been increasing due to the development of industries and the richness of people's lives. One ton of municipal solid waste can produce about 0.05-0.2 tons of leachate during its stay in landfills (Iskander et al. 2018). Landfill leachate has seriously endangered the natural environment and human health (Moradian et al. 2020). Nowadays, the conventional methods for the treatment of landfill leachate at home and abroad include biological method (Lin et al. 2020), electrochemistry oxidation (Li et al. 2011), membrane filtration 
(Keyikoglu et al. 2021) and flocculation method (Cheng et al. 2021). Among them, flocculation method is most commonly employed to purify wastewater due to its obvious advantages of simple operation, good treatment effect, energy saving, environmental friendliness and low cost (Cheng et al. 2021). Typically, inorganic polyaluminum iron chloride (PAFC) flocculant was generally used in industry. Moreover, some research indicates that there is little residual $\mathrm{Al}$ and $\mathrm{Fe}$ in the aquatic solution after treatment (Yan et al. 2016). Whereas, how to reduce the production cost of PAFC through substituting synthetic raw materials, how to further strengthen its treatment efficiency via the optimization of flocculation conditions, and how to improve the quality of PAFC are scientific problems that urgently need to be solved in the application of PAFC. Fortunately, $\mathrm{RM}$ is rich in $\mathrm{Al}_{2} \mathrm{O}_{3}$ and $\mathrm{Fe}_{2} \mathrm{O}_{3}$, which is an excellent raw material for preparing PAFC. This approach can reduce the production cost of PAFC, which is conducive to the further promotion of PAFC.

Accordingly, for this study, solid waste RM was used as raw material, and PAFC was successfully synthesized through a simple and reliable method. The preparation conditions of PAFC were analyzed, including polymerization $\mathrm{pH}$, molar ratios of $\mathrm{Al} / \mathrm{Fe}(\mathrm{n}(\mathrm{Al} / \mathrm{Fe}))$, and polymerization temperature $(\mathrm{T})$. The flocculation performance was evaluated by comparing with the commercial polyaluminum iron chloride flocculant (CPAFC) in the treatment of aged landfill leachate. In addition, the analysis discussed the possible flocculation mechanism of PAFC. This work opened up a new direction for the comprehensive utilization of RM and provided valuable references for the preparation of PAFC and optimization of flocculation conditions.

\section{Materials And Methods \\ 2.1. RM and reagents}

The analytically pure $\mathrm{HCl}, \mathrm{NaOH}, \mathrm{FeCl}_{3} \cdot 6 \mathrm{H}_{2} \mathrm{O}, \mathrm{AlCl}_{3} \cdot 6 \mathrm{H}_{2} \mathrm{O}$ were purchased from Chengdu Kelong Chemical Co., Ltd., and the commercial PAFC (CPAFC) was acquired from Henan Gongyi Shengquan Water Purification Co., Ltd. RM was taken from Chongqing, China, and its chemical composition and phase structure correspond to literature (Cheng et al. 2020). The aged landfill leachate was taken from the Changshengqiao Landfill Site in Chongqing, China $\left(\mathrm{pH}=8.0\right.$, chroma $=3500$ Pt-Co unit, $\mathrm{UV}_{254}=13.0 \mathrm{~cm}^{-}$ 1 , chemical oxygen demand $(C O D)=4482 \mathrm{mg} / \mathrm{L})$. Deionized water was used as experimental water.

\subsection{Preparation of PAFC}

RM was first subjected to acid leaching, and the leaching conditions were as follows: liquid-to-solid ratio of $7, \mathrm{HCl}$ concentration of $5 \mathrm{~mol} / \mathrm{L}$, leaching time of $120 \mathrm{~min}$, and leaching temperature of $70^{\circ} \mathrm{C}$. The concentration of aluminum ion and iron ion in the leaching solution were $6.68 \mathrm{~g} / \mathrm{L}$ and $5.84 \mathrm{~g} / \mathrm{L}$, respectively. Then, the extract was centrifuged at $4000 \mathrm{rpm}$ for $10 \mathrm{~min}$, and the centrifugal supernatant was poured into a $100 \mathrm{~mL}$ beaker. Acid leaching residue, which was used to synthesize NaP1 zeolite to avoid recontamination, has been published in (Cheng et al. 2020). $\mathrm{FeCl}_{3} \cdot 6 \mathrm{H}_{2} \mathrm{O}$ or $\mathrm{AlCl}_{3} \cdot 6 \mathrm{H}_{2} \mathrm{O}$ was added to the beaker to adjust the $\mathrm{n}(\mathrm{Al} / \mathrm{Fe})$ under vigorous magnetic stirring. After dissolution, $3 \mathrm{~mol} / \mathrm{L} \mathrm{NaOH}$ 
was added dropwise to adjust the $\mathrm{pH}$ of the solution. Subsequently, the solution was polymerized for $3 \mathrm{~h}$ at different temperatures and allowed to stand for $12 \mathrm{~h}$. Finally, the standing supernatant was discarded, and the remaining precipitate was dried at $105^{\circ} \mathrm{C}$ for $12 \mathrm{~h}$, and ground to obtain the products PAFC. The synthetic PAFC route is shown in Fig. 1.

\subsection{Characterization}

NicoletiS50 Fourier Transform Infrared Spectrometer (FTIR) was used to characterize the sample structure. X-ray diffraction (XRD) patterns of all samples were obtained using a Shimadzu XRD-6000 Xray diffractometer (measurement conditions: target $\mathrm{Cu}$, tube voltage $40 \mathrm{~V}$, tube current $40 \mathrm{~mA}$, scan range $5^{\circ}-90^{\circ}$, SpectrisPte, Netherlands). Scanning electron microscopy (Eterigho-lkelegbe et al.) analyses were performed on a FEI NOVA 400 scanning electron microanalyzer (field emission, resolution $1 \mathrm{~nm}$ ) with an energy dispersive $\mathrm{X}$-ray spectroscope (EDS).

\subsection{Flocculation performance test}

The COD and chroma tests were done according to the HJ 828-2017 standard and the GB 11903-89 standard (Xu et al. 2015), respectively. The $U_{2} V_{254}$ absorbance $\left(\mathrm{cm}^{-1}\right)$ of the leachate sample has been tested by a TU1901 spectrometer (Persee, Beijing, China). For the determination of the COD, UV 254 and chroma removal efficiency, first take $50 \mathrm{~mL}$ of landfill leachate diluted 2 times and put it into a $100 \mathrm{~mL}$ graduated cylinder. Then, $10 \mathrm{~mL}$ of flocculant with a certain flocculation concentration was slowly dropped into the graduated cylinder under mechanical stirring. After dripping, mechanically stir at 500 $\mathrm{r} / \mathrm{min}$ for $2 \mathrm{~min}$, and then at $150 \mathrm{r} / \mathrm{min}$ for $5 \mathrm{~min}$. The supernatant at the liquid level below $3 \mathrm{~cm}$ after standing for 90 min was used to measure the COD, UV 254 and chroma. The COD, $\mathrm{UV}_{254}$ and chroma removal efficiency of the landfill leachate Eq. (1) (Cheng et al. 2021):

$$
\text { Removal efficiency }(\%)=\frac{\left(c_{0}-C_{t}\right)}{c_{0}} \times 100 \%
$$

Where: $\mathrm{C}_{0}$ is the initial the $\mathrm{COD}, \mathrm{UV}_{254}$ or chroma value of the non-treated wastewater and $\mathrm{C}_{\mathrm{t}}$ is the COD, $\mathrm{UV}_{254}$ or chroma value measured in the effluent at $90 \mathrm{~min}$.

After flocculation stirring was stopped, and the scale value of the interface $\left(V_{t}\right)$ was recorded at continuous time intervals. The settlement height $(\mathrm{SH})$ and settlement velocity (Belviso et al.) could be calculated as follows (Wang et al. 2020a):

$$
\begin{aligned}
& S H=\frac{\left(V_{0}-V_{t}\right)}{\pi r^{2}} \\
& S H=\frac{S H}{t}
\end{aligned}
$$

Where: $V_{0}$ is the initial scale value of the interface after stirring; $r$ is the internal radius of measuring cylinder $(23.0 \mathrm{~mm})$; $\mathrm{t}$ is the flocculation settling time $(\mathrm{s})$.

\section{Results And Discussion}




\subsection{Optimization of preparation parameters}

In order to determine the optimum conditions for PAFC synthesis, the influences of different polymerization $\mathrm{pH}, \mathrm{n}(\mathrm{Al} / \mathrm{Fe})$ and $\mathrm{T}$ on the flocculation performance under flocculation $\mathrm{pH}$ of 8 and flocculant addition concentration of $50 \mathrm{~g} / \mathrm{L}$ were discussed. $\mathrm{pH}$ plays an indispensable role in the preparation of PAFC. A low pH is not conducive to hydrolysis and polymerization, while a high $\mathrm{pH}$ easily causes a large amount of hydroxide sol and precipitation (Yan et al. 2016). Therefore, the influence of different $\mathrm{pH}$ on the COD removal efficiency of landfill leachate was explored. As shown in Fig. 2, the COD removal efficiency first raised and then decreased with increasing $\mathrm{pH}$. The optimum COD removal efficiency was $48.5 \%$ at $\mathrm{pH}$ of 2.5 . As $2<\mathrm{pH}<2.5$, the increase in $\mathrm{pH}$ promoted the hydrolysis and polymerization of $\mathrm{Fe}^{3+}$ and $\mathrm{Al}^{3+}$, resulting in more macromolecular polymers (X et al. 2000). However, 2.5 $<\mathrm{pH}<5.0$, the COD removal efficiency decreased significantly, which may be related to the increase in the number of hydroxide sols or precipitates. To ensure the excellent COD removal efficiency and reduce the amount of $\mathrm{pH}$ adjustment, $\mathrm{pH}$ of 2.5 was selected as the most suitable preparation condition for further study.

Shown in Fig. 3 is the results on the effect of $n(\mathrm{Al} / \mathrm{Fe})$ on the COD removal. The COD removal efficiency of PAFC increased with the increase of $n(\mathrm{Al} / \mathrm{Fe})$ continuously, and achieved above $50 \%$ at $n(\mathrm{Al} / \mathrm{Fe})$ of 8 . High $\mathrm{n}(\mathrm{Al} / \mathrm{Fe})$ was beneficial to increase the number of water molecules in the coordination of aluminumiron copolymer (Zhu et al. 2011). The central charge of hydroxyl groups gradually deviated from the iron core, and the aluminum-iron core of the copolymer was easy to form a balance and the stability was improved (Jiang \&Graham 2003). Considering the COD removal and cost of reagent addition, $n(\mathrm{Al} / \mathrm{Fe})$ of 8 was selected as the optimum synthesis condition.

The flocculation performance of PAFC prepared in the reaction temperature range of $40^{\circ} \mathrm{C}-80^{\circ} \mathrm{C}$ and the interval of $10^{\circ} \mathrm{C}$ was investigated. The COD removal results are shown in Fig. 4. It was found that the COD removal efficiency of landfill leachate increased with the increasing $\mathrm{T}$, and the optimum COD removal efficiency of $51.4 \%$ appeared at $70^{\circ} \mathrm{C}$. However, as the temperature continues to rise, the COD removal efficiency has shown a downward trend. As we all know, the hydrolysis and polymerization in the reaction process are endothermic and exothermic processes respectively (Yan et al. 2016). $\mathrm{T}<70^{\circ} \mathrm{C}$, the increased temperature enhanced the hydrolysis of $\mathrm{Fe}^{3+}$ and $\mathrm{Al}^{3+}$, and the content of polymerized monomers in the hydroxylated state also raised. The charges and molecular chains carried by PAFC increase continuously, which improved the charge neutralization and adsorption bridging of PAFC during the flocculation process. Hence, the flocculation performance was optimized with the increasing T (Yan et al. 2016). Nevertheless, the performance of the synthesized flocculant became worse when the reaction temperature was more than $70^{\circ} \mathrm{C}$. On the one hand, the influence of polymerization was greater than that of hydrolysis due to excessive polymerization temperature (Yang et al. 2019). On the other hand, with a further increase in the reaction temperature, the rate of precipitate formation was increased, which attributed to the hydrolyzation and sedimentation of $\mathrm{Fe}^{3+}$ and $\mathrm{Al}^{3+}$ in PAFC product (Liu et al. 2020). For better flocculation effect and energy conservation, $70^{\circ} \mathrm{C}$ was selected as the polymerization temperature 
for PAFC preparation in the next step. Hence, the PAFC synthesized at $\mathrm{pH}$ of $2.5, \mathrm{n}(\mathrm{Al} / \mathrm{Fe})$ of 8 , and polymerization temperature of $70^{\circ} \mathrm{C}$ was employed to study the flocculation conditions.

\subsection{Optimization of flocculation parameters}

The added concentration of flocculant and the initial $\mathrm{pH}$ of the landfill leachate were analyzed to obtain the optimum flocculation parameters, and the COD removal efficiency is shown in Fig. 5. Figure 5(a) shows the COD removal efficiency of landfill leachate with different flocculant addition concentrations. The COD removal efficiency rose with the increasing concentration, and all showed a significant trend, which may lead to increased adsorption and bridging (Lundström-Hämälä et al. 2010). When PAFC > 60 $\mathrm{g} / \mathrm{L}$, however, the COD removal efficiency tended to be stable. This phenomenon was explained as the neutralized negatively charged colloidal particles were recharged positively due to adsorption. The increased repulsive force between particles and the difficulty of adsorption bridging caused the flocculation system to regain stability (Shuang et al. 2020). Therefore, there was an optimum polymer dosing range for a given system (Bolto 1995). The flocculation concentration of $60 \mathrm{~g} / \mathrm{L}$ was used as the optimum concentration to reduce the amount of flocculant added and maintain excellent flocculation capacity.

The initial $\mathrm{pH}$ of the landfill leachate was adjusted to the set value with $0.5 \mathrm{~mol} / \mathrm{L} \mathrm{HCl}$ and $0.5 \mathrm{~mol} / \mathrm{L}$ $\mathrm{NaOH}$, and the relationship between the initial $\mathrm{pH}$ of the landfill leachate and the performance of the PAFC flocculant was studied. As shown in Fig. 5(b), the initial pH of the landfill leachate had a significant effect on the flocculation capacity. $\mathrm{pH}<6$, a large amount of $\mathrm{H}^{+}$in the solution reacted with $-\mathrm{OH}$ in the polymer, which reduced the degree of polymerization of the hydrolyzed complex and led to the inhibition of flocculation [14]. $\mathrm{pH}=6$, the low charge positive ions generated by PAFC hydrolysis produced adhesion bridging and net capture and sweep effect on the unstable particles, so the flocculation performance was excellent and similar results have been reported in the literature (Ghani et al. 2017, Matilainen et al. 2010). The maximum COD removal efficiency of CPAFC and PAFC at pH of 6 was $73.0 \%$ and $72.2 \%$, respectively. $\mathrm{pH}>6$, the flocculation performance deteriorated may be due to the decrease of the stability of the flocculant with the increase of $-\mathrm{OH}$. According to the above results, the flocculation concentration of 60 $\mathrm{g} / \mathrm{L}$ and $\mathrm{pH}$ of 6 was applied as the optimum flocculation parameters.

The zone SV was determined in the flocculation. The zone SV was calculated by taking into account the linear regression values of the initial settling stage, however, the transition and compression settling stages were ignored (Chhuon et al. 2020). By recording the $\mathrm{V}_{t}$ at different settling times, the relationship between SH and settling time was obtained, as shown in Fig. 6(a). Figure 6(b) plots the relationship between SV and settlement time during the settlement within $90 \mathrm{~min}$. The interface height of PAFC decreased rapidly between 0 and $10 \mathrm{~min}$, whereas, the change of CPAFC was not obvious. The linear fitting results in the initial settlement stage are shown in the illustration of Fig. 6 (a). The fitting correlation coefficient of PAFC was as high as 0.978 , while the result of CPAFC was not satisfactory. The solid-liquid interface of flocs dropped rapidly, and the SV increased to the maximum with PAFC and 
CPAFC in 0 to $10 \mathrm{~min}$. In this stage, the floc particles completed the accelerated settlement process (Wang et al. 2020a).

The COD, $\mathrm{UV}_{254}$, chroma and SV under the optimum flocculation conditions were measured to compare the flocculation performance of CPAFC and PAFC. The COD removal efficiency of CPAFC and PAFC were $73.0 \%$ and $72.2 \%$, respectively. Similarly, the $\mathrm{UV}_{254}$ removal efficiency of CPAFC and PAFC were $79.9 \%$ and $79.2 \%$, respectively; the chroma removal efficiency were $85.7 \%$ and $82.9 \%$, respectively. Self-made PAFC and commercial PAFC had similar removal effects on landfill leachate. It is worth noting that the maximum SV of PAFC $(0.72 \mathrm{~cm} / \mathrm{min})$ was significantly higher than that of CPAFC $(0.12 \mathrm{~cm} / \mathrm{min})$. The measured flocculation indexes confirmed that the flocculation performance of PAFC on landfill leachate could reach the effect of CPAFC. Moreover, self-made PAFC had more advantages than commercial flocculant in terms of SV. The results showed that PAFC had excellent removal effect on high concentration the COD and refractory wastewater, suggesting that was a promising wastewater purification reagent.

\subsection{Samples characterization and flocculation mechanism 3.2.1. FTIR}

Chemical structure of the as-synthesized PAFC and PAFC treated flocs samples were analyzed by FI-IR spectroscopy and the Fig. 7 shows the FT-IR spectra. The broad absorption peak between $3400-3500$ $\mathrm{cm}^{1}$ belonged to the stretching vibration of the $-\mathrm{OH}$ groups $(\mathrm{Al}-\mathrm{OH}, \mathrm{Fe}-\mathrm{OH})$ attached to $\mathrm{Al}, \mathrm{Fe}$ or the $-\mathrm{OH}$ groups of the water molecules in the sample (Zhang et al. 2015). Another sharp peak observed at 1620$1640 \mathrm{~cm}^{1}$ also indicated the bending vibration attributed to hydroxyl group within $\mathrm{Al}-\mathrm{OH}, \mathrm{Fe}-\mathrm{OH}$, adsorbed water or crystal water (Ghani et al. 2017, Xinhua et al. 2006). For the PAFC sample, two weak absorption peaks appeared at $1099 \mathrm{~cm}^{1}$ and $966 \mathrm{~cm}^{1}$, which may be related to the asymmetric stretching vibration of the Fe-OH-Fe and Al-OH-Al bonds (Baozhen \&Hongxiao 1990, Wang et al. 2020b). The vibration absorption peak at $603 \mathrm{~cm}^{1}$ was caused by the spatial bending vibration of $\mathrm{Al}-\mathrm{OH}$ and $\mathrm{Fe}-\mathrm{OH}$. These results indicated that the PAFC composites had characteristics of $\mathrm{Fe}^{3+}$ and $\mathrm{Al}^{3+}$ inorganic flocculant, supporting the conclusion that the iron and aluminum complexes had formed (Yang et al. 2019). The absorption peak at $1406 \mathrm{~cm}^{1}$ belonging to the flocs was assigned to the $\mathrm{Al}-\mathrm{OH}$ in-plane bending vibration absorption peak. The peaks at $896 \mathrm{~cm}^{1}$ and $482 \mathrm{~cm}^{1}$ in the flocs were attributed to the bending vibration of $\mathrm{Fe}-\mathrm{OH}-\mathrm{Fe}$ and the peak of $\mathrm{Fe}-\mathrm{OH} / \mathrm{Al}-\mathrm{OH}$ respectively, which confirmed that there were still Fe-Al polymers in the flocs. In the FTIR spectrum of the flocs, the two characteristic absorption peaks at 1071 $\mathrm{cm}^{1}$ and $625 \mathrm{~cm}^{1}$ were caused by the shift of $1099 \mathrm{~cm}^{1}$ and $603 \mathrm{~cm}^{1}$, respectively, suggesting that Al-OH and $\mathrm{Fe}-\mathrm{OH}$ in PAFC were involved in the flocculation process. FTIR spectra showed that there was occurrence of similar functional groups between PAFC sample and flocs but the relative intensity of transmittance and wavenumber position varied due to physicochemical interaction between flocs and active groups in PAFC (Ghani et al. 2017).

\subsubsection{XRD}


XRD patterns of PAFC and flocs were depicted in Fig. 8. PAFC had $\beta-F e O(O H)$ (JCPDS NO.39-0612) and $\mathrm{AlCl}_{3} \cdot 6 \mathrm{H}_{2} \mathrm{O}$ (JCPDS N0.08-0453), which illustrated that $\mathrm{Al}^{3+}$ and $\mathrm{Fe}^{3+}$ polymers first evolved into $\mathrm{Cl}$ containing amorphous iron hydroxy sol and hydroxy aluminum sol. Simultaneously, the characteristic diffraction peak of $\mathrm{Al}_{13} \mathrm{Cl}_{15}(\mathrm{OH})_{24} \cdot 37.5 \mathrm{H}_{2} \mathrm{O}$ (JCPDS NO.20-0026) was observed at $2 \theta=17.5^{\circ}$, which may be due to the appearance of the Keggin structure peak of $\mathrm{Al}_{13}$ phase with the extension of polymerization time (Duan \&Gregory 2003, Zhao et al. 1993). These hydroxide hydrate compounds contain typical functional groups of - $\mathrm{OH}, \mathrm{Fe}-\mathrm{OH}, \mathrm{Al}-\mathrm{OH}-\mathrm{Al}, \mathrm{Al}-\mathrm{O}-\mathrm{Al}, \mathrm{Fe}-\mathrm{O}$, and $\mathrm{Al}-\mathrm{O}$, which were consistent with the results of the FT-IR spectroscopy analyses. The strong $\mathrm{NaCl}$ (JCPDS N0.78-0751) crystalline peaks in PAFC were found. However, $\mathrm{NaCl}$ in PAFC could not significantly affect flocculation and water bodies (Yan et al. 2016). Moreover, only $\mathrm{NaCl}$ characteristic diffraction peaks were observed in the XRD pattern of the flocs, which indicated that the crystals containing $\mathrm{Al}$ and Fe participated in the reaction during the flocculation, while the $\mathrm{NaCl}$ of PAFC mostly existed in water as flocs.

\subsubsection{SEM and EDS}

Figure 9 is the SEM images of PAFC, the SEM image (e-f) of the floc, the EDS scanning surface (g) and the EDS spectrum (i). In Fig. 9(a), (b), it was observed that PAFC had a clear metallic luster and smooth surface. From Fig. 9(c), the brushed shape was found, which may be due to the incomplete formation of Fe-Al polymerization. In addition, the amorphous Fe-Al hydroxyl compound chain micelles were interwoven to form an obvious grid structure in Fig. 9(d). The grid structure of PAFC effectively promoted the flocculation effect (Wang et al. 2020b). As shown in Fig. 9(e), (f), (g), it can be observed that the flocs presented complex and diverse morphologies, including spherical, granular and massive. Also, the SEM images shows that the flocs were well and compact in nature (Cheng et al. 2021). The compact flocs structure was helpful to accelerate the settlement speed, which should be consistent with the sedimentation results. The rough and non-uniformly distributed structure also showed that aggregation of leachate particle has taken place and flocculation process (Teh et al. 2014). EDS scanning is carried out for Fig. 9(h), and the results are shown in Fig. 9(i). Fe, $\mathrm{Al}, \mathrm{O}, \mathrm{Na}, \mathrm{Ca}$ and $\mathrm{Cl}$ elements were presented in PAFC. It is worth noting that the characteristic energy spectrum of Ca element existed in PAFC, which may be formed after acid leaching of Ca-containing minerals. The above morphology and elemental analysis results confirmed that PAFC was successfully prepared.

\subsubsection{Mechanism analysis}

Through the phase, morphology and structure analysis before and after flocculation, the possible flocculation mechanism of PAFC is shown in Fig. 10. The flocculant rapidly hydrolyzed and polymerized in the solution, and then interacted with colloidal or suspended particles in the landfill leachate to cause related physical-chemical reactions. PAFC was positively charged through hydrolysis (Duan \&Gregory 2003), and then the negative charge was absorbed by charge neutralization (including 'electrostatic patch' effects) (Bolto \&Gregory 2007) and adsorption (Xue et al. 2019) to destabilize the colloidal particles in the solution to form large particles. PAFC could adsorb to particles in the electric neutralization and adsorption stages, and form bridges between particles (Bolto 1995). The chain-like structures are interlaced to become a dense network of flocs (Gregory \&Dupont 2001). When the density 
of the flocs is greater than that of water, the flocs begin to settle. During the sedimentation process, the dense network structure continues to trap and sweep the fine particles in the solution, which promotes the continuous increase of the volume of the floc particles (Duan \&Gregory 2003). The increased volume causes the settling speed to increase, thereby achieving the desired flocculation result.

\section{Conclusion}

PAFC was successfully synthesized using RM acid leaching solution. PAFC prepared under the optimum conditions, including $\mathrm{pH}$ of $2.5, \mathrm{Al} / \mathrm{Fe}$ molar ratio of 8 , and polymerization temperature of $70^{\circ} \mathrm{C}$, was used to treat landfill leachate. Comparing the COD, $\mathrm{UV}_{254}$, and SV flocculation indicators of PAFC and CPAFC, the results confirmed that PAFC had excellent flocculation effect on the aged landfill leachate. In addition, the possible flocculation mechanism of PAFC was discussed. Electric neutralization adsorption, bridging and net trapping and sweeping constituted the PAFC flocculation process, which achieved the desired flocculation results of pollutants. It is anticipated that the results of the current investigation can help to open new paths to explore more lower-cost PAFC preparation processes for real world applications.

\section{Declarations}

Authors' contributions: Yong Cheng: Conceptualization, Methodology and Writing-Original Draft; Zao Jiang: Investigation; Longjun Xu and Chenglun Liu: Resources and Supervision; Yong Cheng, Zao Jiang, Qiyuan Zhang, Yi Zhou and Yan Chen: Software; Yong Cheng, Longjun Xu and Chenglun Liu: WritingReview\&Editing; Yong Cheng, Jingya Li and Xiuzhu Liu: Data Curation, Visualization. All authors read and approved the final manuscript.

Funding: The authors are the financial supported by the independent research project of State Key Laboratory of Coal Mine Disaster Dynamics and Control (2011DA105287-zd201904).

Data availability: The datasets used and/or analyzed during the current study are available from the corresponding author on reasonable request.

\section{Compliance with ethical standards}

Ethical approval and consent to participate: Not applicable.

Consent to publication: Not applicable.

Competing interests: The authors declare that they have no competing interests.

\section{References}

1. Alam S, Das SK, Rao BH (2019): Strength and durability characteristic of alkali activated GGBS stabilized red mud as geo-material. Constr. Build. Mater. 211:932-942 
2. Baderna D, Caloni F, Benfenati E (2019): Investigating landfill leachate toxicity in vitro: A review of cell models and endpoints. Environment International 122:21-30

3. Baozhen T, Hongxiao T (1990): Infrared spectra and electrical conductivity of polymeric $\mathrm{Fe}(\mathbb{Z})$ species. Environ. Chem. 9(06):70-76

4. Belviso C, Kharchenko A, Agostinelli E, Cavalcante F, Peddis D, Varvaro G, Yaacoub N, Mintova S (2018): Red mud as aluminium source for the synthesis of magnetic zeolite. Microporous Mesoporous Mater 270:24-29

5. Bolto B, Gregory J (2007): Organic polyelectrolytes in water treatment. Water Res. 41(11):2301-2324

6. Bolto BA (1995): Soluble polymers in water purification. Prog. Polym. Sci. 20(6):987-1041

7. Cheng SY, Show P-L, Juan JC, Chang J-S, Lau BF, Lai SH, Ng EP, Yian HC, Ling TC (2021): Landfill leachate wastewater treatment to facilitate resource recovery by a coagulation-flocculation process via hydrogen bond. Chemosphere 262:127829

8. Cheng Y, Xu L, Jiang Z, Liu C, Zhang Q, Zou Y, Chen Y, Li J, Liu X (2020): Feasible low-cost conversion of red mud into magnetically separated and recycled hybrid $\mathrm{SrFe}_{12} \mathrm{O}_{19} @ \mathrm{NaP} 1$ zeolite as a novel wastewater adsorbent. Chem. Eng. J. 128090

9. Chhuon R, Shahid MK, Kim S, Choi Y (2020): Mill scale as a ballasted flocculant for enhancing the settleability of activated sludge. J. Environ. Chem. Eng. 8(5):104237

10. Ding X, Xu G, Zhou W, Kuruppu M (2020): Effect of synthetic and natural polymers on reducing bauxite residue dust pollution. Environ. Technol. 41(5):556-565

11. Duan J, Gregory J (2003): Coagulation by hydrolysing metal salts. Adv. Colloid Interface Sci. 100102:475-502

12. Eterigho-lkelegbe O, Bada S, Daramola MO, Falcon R (2020): Synthesis of high purity hydroxy sodalite nanoparticles via pore-plugging hydrothermal method for inorganic membrane development: Effect of synthesis variables on crystallinity, crystal size and morphology. Mater. Today: Proc.

13. Gelencser A, Kovats N, Turoczi B, Rostasi A, Hoffer A, Imre K, Nyiro-Kosa I, Csakberenyi-Malasics D, Toth A, Czitrovszky A, Nagy A, Nagy S, Acs A, Kovacs A, Ferincz A, Hartyani Z, Posfai M (2011): The Red Mud Accident in Ajka (Hungary): Characterization and Potential Health Effects of Fugitive Dust. Sci. Total Environ. 45(4):1608-1615

14. Ghani ZA, Yusoff MS, Zaman NQ, Zamri MFMA, Andas J (2017): Optimization of preparation conditions for activated carbon from banana pseudo-stem using response surface methodology on removal of color and COD from landfill leachate. Waste Manage. 62:177-187

15. Gregory J, Dupont V (2001): Properties of flocs produced by water treatment coagulants. Water Sci. Technol. 44(10):231-236

16. Iskander SM, Zhao R, Pathak A, Gupta A, Pruden A, Novak JT, He Z (2018): A review of landfill leachate induced ultraviolet quenching substances: Sources, characteristics, and treatment. Water Res. 145:297-311 
17. Jiang JQ, Graham NJD (2003): Development of Optimal Poly-Alumino-Iron Sulphate Coagulant. J. Environ. Sci. 129(8):699-708

18. Keyikoglu R, Karatas O, Rezania H, Kobya M, Vatanpour V, Khataee A (2021): A review on treatment of membrane concentrates generated from landfill leachate treatment processes. Sep. Purif. Technol. 259:118182

19. Khairul MA, Zanganeh J, Moghtaderi B (2019): The composition, recycling and utilisation of Bayer red mud. Resour. Conserv. Recycl. 141:483-498

20. Kovacs T, Sas Z, Jobbagy V, Csordas A, Szeiler G, Somlai J (2013): Radiological aspects of red mud disaster in Hungary. Acta Geophys. 61(4):1026-1037

21. Li X, Song J, Guo J, Wang Z, Feng Q (2011): Landfill leachate treatment using electrocoagulation. Procedia Environ. Sci. 10:1159-1164

22. Lin H, Peng H, Feng X, Li X, Zhao J, Yang K, Liao J, Cheng D, Liu X, Lv S, Xu J, Huang Q (2020): Energy-Efficient for Advanced Oxidation of Bio-treated Landfill Leachate Effluent by Reactive Electrochemical Membranes (REMs): Laboratory and Pilot Scale Studies. Water Res.:116790

23. Liu B, An P, Chen J, Xu X, Liu L, Yang F (2020): A novel method for preparation of polyaluminum phosphoric sulfate (PAPS) coagulant using SAPO-34 mother liquor: Characterization and coagulation performance. Process Saf. Environ. Prot. 140:380-391

24. Liu W, Chen X, Li W, Yu Y, Yan K (2014): Environmental assessment, management and utilization of red mud in China. J. Cleaner Prod. 84:606-610

25. Lundström-Hämälä L, Johansson E, Wågberg L (2010): Polyelectrolyte Multilayers from Cationic and Anionic Starch: Influence of Charge Density and Salt Concentration on the Properties of the Adsorbed Layers. Starch - Stärke 62(2):102-114

26. Matilainen A, Vepsäläinen $M$, Sillanpää $M$ (2010): Natural organic matter removal by coagulation during drinking water treatment: A review. Adv. Colloid Interface Sci. 159(2):189-197

27. Mayes WM, Burke IT, Gomes HI, Anton AD, Molnar M, Feigl V, Ujaczki E (2016): Advances in Understanding Environmental Risks of Red Mud After the Ajka Spill, Hungary. J. Sustain. Metall. 2(4):332-343

28. Moradian F, Ramavandi B, Jaafarzadeh N, Kouhgardi E (2020): Effective treatment of high-salinity landfill leachate using ultraviolet/ultrasonication/ peroxymonosulfate system. Waste Manage. 118:591-599

29. Power G, Gräfe M, Klauber C (2011): Bauxite residue issues: I. Current management, disposal and storage practices. Hydrometallurgy 108(1):33-45

30. Samal S, Ray AK, Bandopadhyay A (2013): Proposal for resources, utilization and processes of red mud in India - A review. Int. J. Miner. Process. 118:43-55

31. Samsudin MFR, Bashiri R, Mohamed NM, Ng YH, Sufian S (2020): Tailoring the morphological structure of $\mathrm{BiVO}_{4}$ photocatalyst for enhanced photoelectrochemical solar hydrogen production from natural lake water. Appl. Surf. Sci. 504:144417 
32. Shuang Z, Mengchen X, Yan W (2020): Preparation, application and coagulation mechanism of polyaluminium ferric chloride. Inorg. Chem. Ind. 52(7):36-41

33. Teh CY, Wu TY, Juan JC (2014): Potential use of rice starch in coagulation-flocculation process of agro-industrial wastewater: Treatment performance and flocs characterization. Ecological Engineering 71:509-519

34. Wang D-I, Zhang Q-I, Chen Q-S, Qi C-c, Feng Y, Xiao C-C (2020a): Temperature variation characteristics in flocculation settlement of tailings and its mechanism. Int. J. Miner. Metall. Mater. 27(11):14381448

35. Wang X, Zhang N, Zhang Y, Liu J, Xiao X, Meng K, Chu B, Wang C, Chu PK (2020b): Multiple flocculant prepared with dealkalized red mud and fly ash: Properties and characterization. Journal of Water Process Engineering 34:101173

36. Winkler D, Bidlo A, Bolodar-Varga B, Erdo A, Horvath A (2018): Long-term ecological effects of the red mud disaster in Hungary: Regeneration of red mud flooded areas in a contaminated industrial region. Sci. Total Environ. 644:1292-1303

37. X Z, Y Z, H F, G Y, Y L, D H (2000): Study of polyaluminium ferric chloride (PAFC) aqueous solutions visible spectra: the relationship among their absorbance at $460 \mathrm{~nm}$, basicities and total $\mathrm{Fe}(\mathrm{III})$ concentration of PAFC solutions. Spectrosc. Spectral Anal. 20(4):577-80

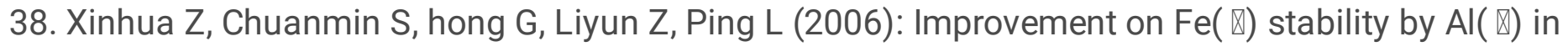
polyaluminum ferric chloride solutions. Acta Mineral. Sin. 26(01):47-52

39. Xu P, Han H, Zhuang H, Hou B, Jia S, Xu C, Wang D (2015): Advanced treatment of biologically pretreated coal gasification wastewater by a novel integration of heterogeneous Fenton oxidation and biological process. Bioresour. Technol. 182:389-392

40. Xue S, Kong X, Zhu F, Hartley W, Li X, Li Y (2016a): Proposal for management and alkalinity transformation of bauxite residue in China. Environ. Sci. Pollut. Res. 23(13):12822-12834

41. Xue S, Zhu F, Kong X, Wu C, Huang L, Huang N, Hartley W (2016b): A review of the characterization and revegetation of bauxite residues (Red mud). Environ. Sci. Pollut. Res. 23(2):1120-1132

42. Xue Y, Liu Z, Li A, Yang H (2019): Application of a green coagulant with PACl in efficient purification of turbid water and its mechanism study. J. Environ. Sci. 81:168-180

43. Yan L, Wang Y, Li J, Shen H, Zhang C, Qu T (2016): Preparation of polymeric aluminum ferric chloride (PAFC) coagulant from fly ash for the treatment of coal-washing wastewater. Desalin. Water Treat. 57(39):18260-18274

44. Yang S, Li W, Zhang H, Wen Y, Ni Y (2019): Treatment of paper mill wastewater using a composite inorganic coagulant prepared from steel mill waste pickling liquor. Sep. Purif. Technol. 209:238-245

45. Zhang Y, Li S, Wang X, Ma X, Wang W, Li X (2015): Synthesis, purification and characterization of polyaluminum ferric chloride (PAFC) with high (Al+Fe)b content. Sep. Purif. Technol. 146:311-316

46. Zhao D, Wang G, Yang Y, Guo X, Wang Q, Ren J (1993): Preparation and Characterization of HydroxyFeal Pillared Clays. Clays Clay Miner. 41(3):317-327 
47. Zhu G, Zheng H, Zhang Z, Tshukudu T, Zhang P, Xiang X (2011): Characterization and coagulationflocculation behavior of polymeric aluminum ferric sulfate (PAFS). Chem. Eng. J. 178:50-59

\section{Figures}

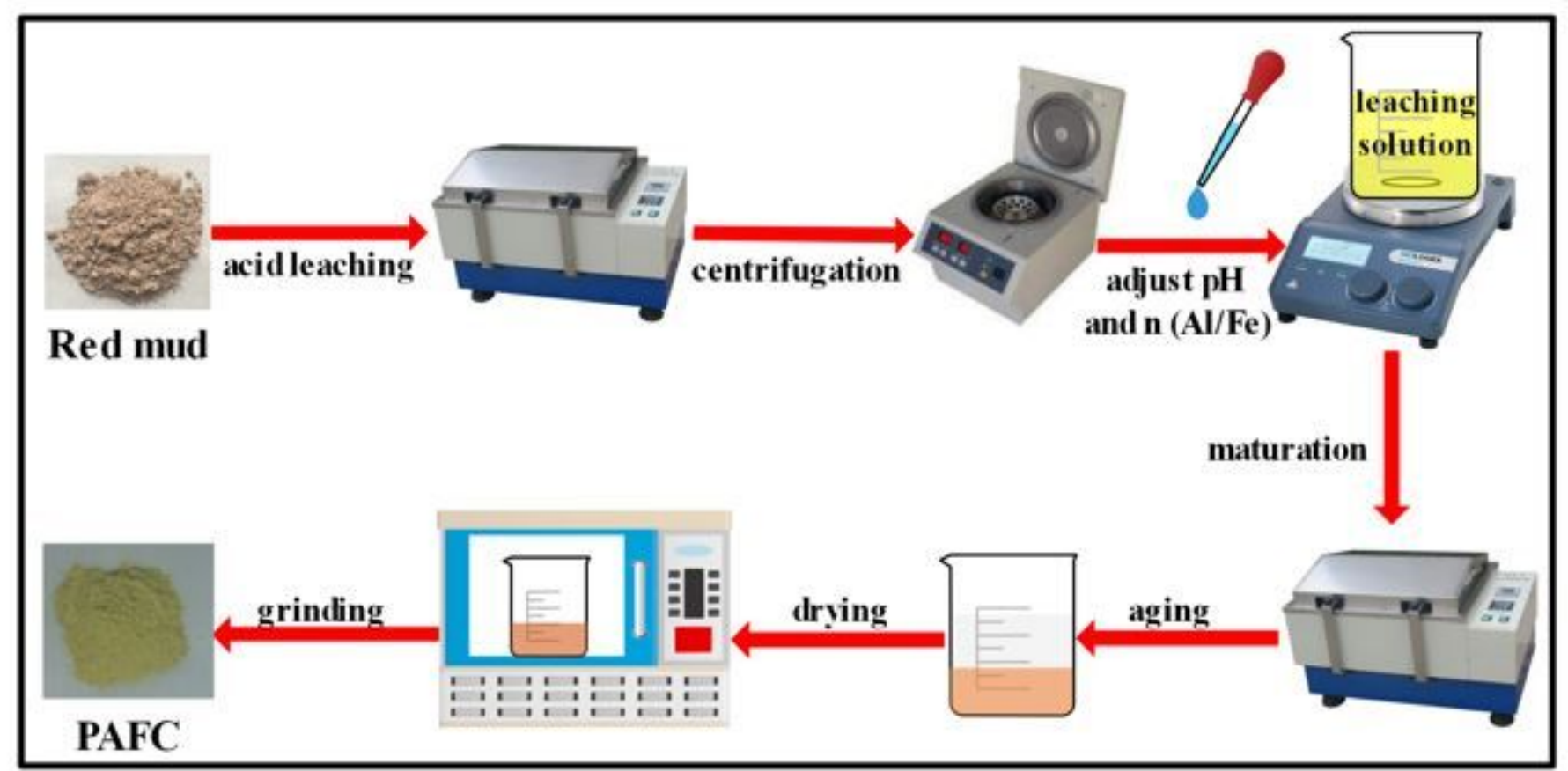

Figure 1

A schematic illustration for facile fabrication of the PAFC. 


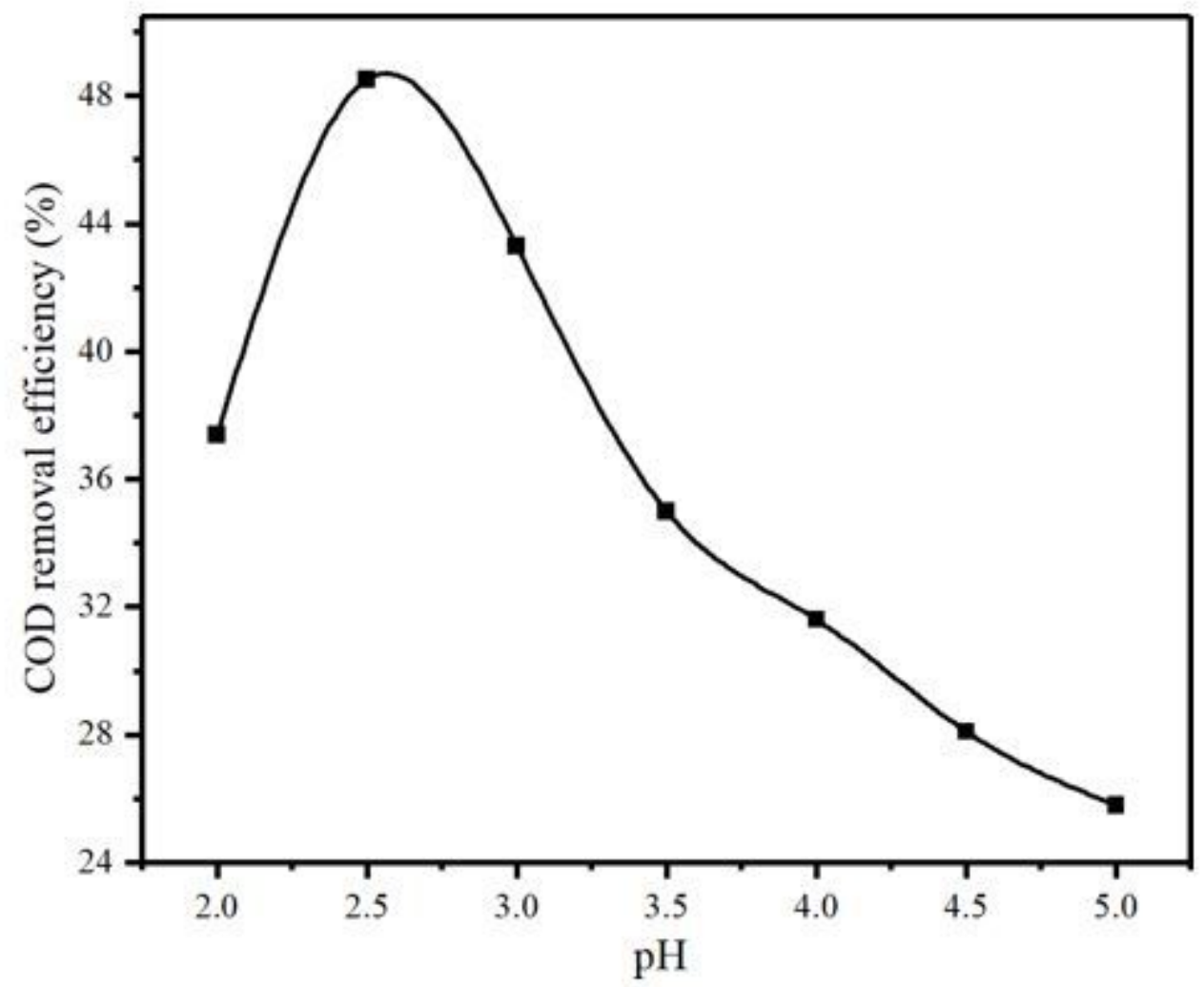

Figure 2

The effect of PAFC preparation $\mathrm{pH}$ on the COD removal efficiency of landfill leachate $(\mathrm{n}(\mathrm{Al} / \mathrm{Fe})=6, \mathrm{~T}=$ $\left.60^{\circ} \mathrm{C}\right)$. 


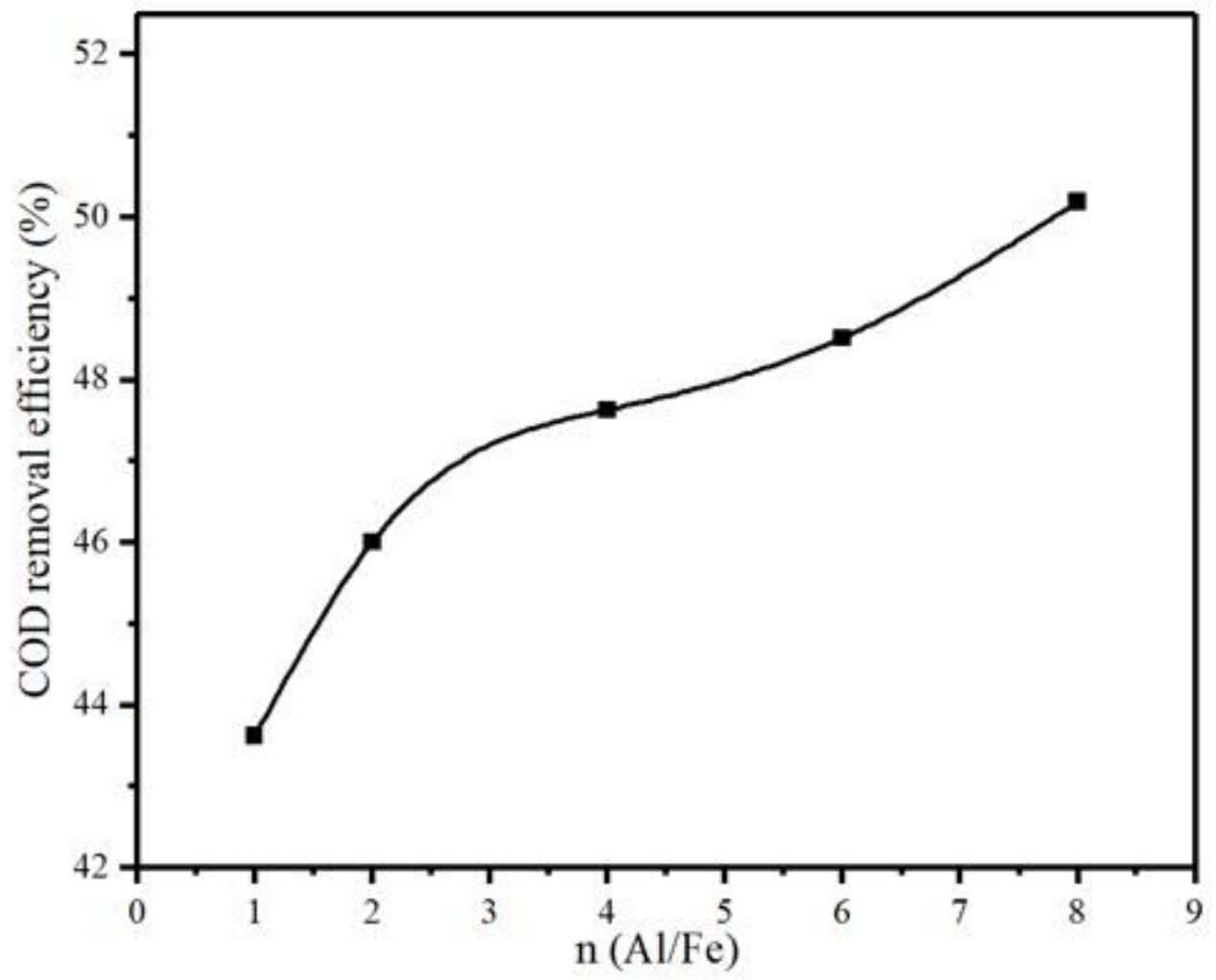

Figure 3

The effect of PAFC preparation $\mathrm{n}(\mathrm{Al} / \mathrm{Fe})$ on the COD removal efficiency of landfill leachate $(\mathrm{pH}=2.5, \mathrm{~T}=$ $\left.60^{\circ} \mathrm{C}\right)$. 


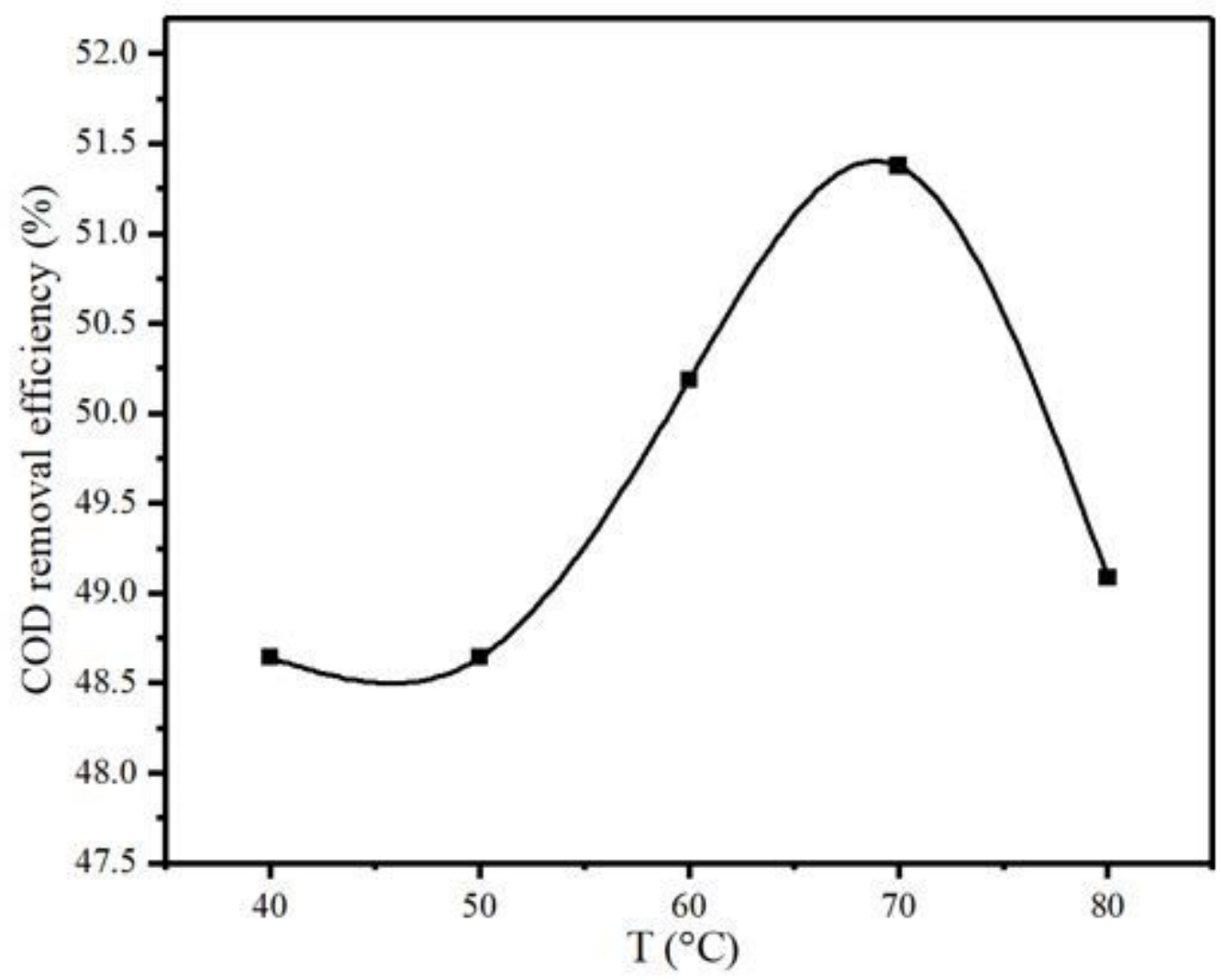

Figure 4

The effect of PAFC preparation T on the COD removal efficiency of landfill leachate $(\mathrm{n}(\mathrm{Al} / \mathrm{Fe})=8, \mathrm{pH}=$ 2.5).
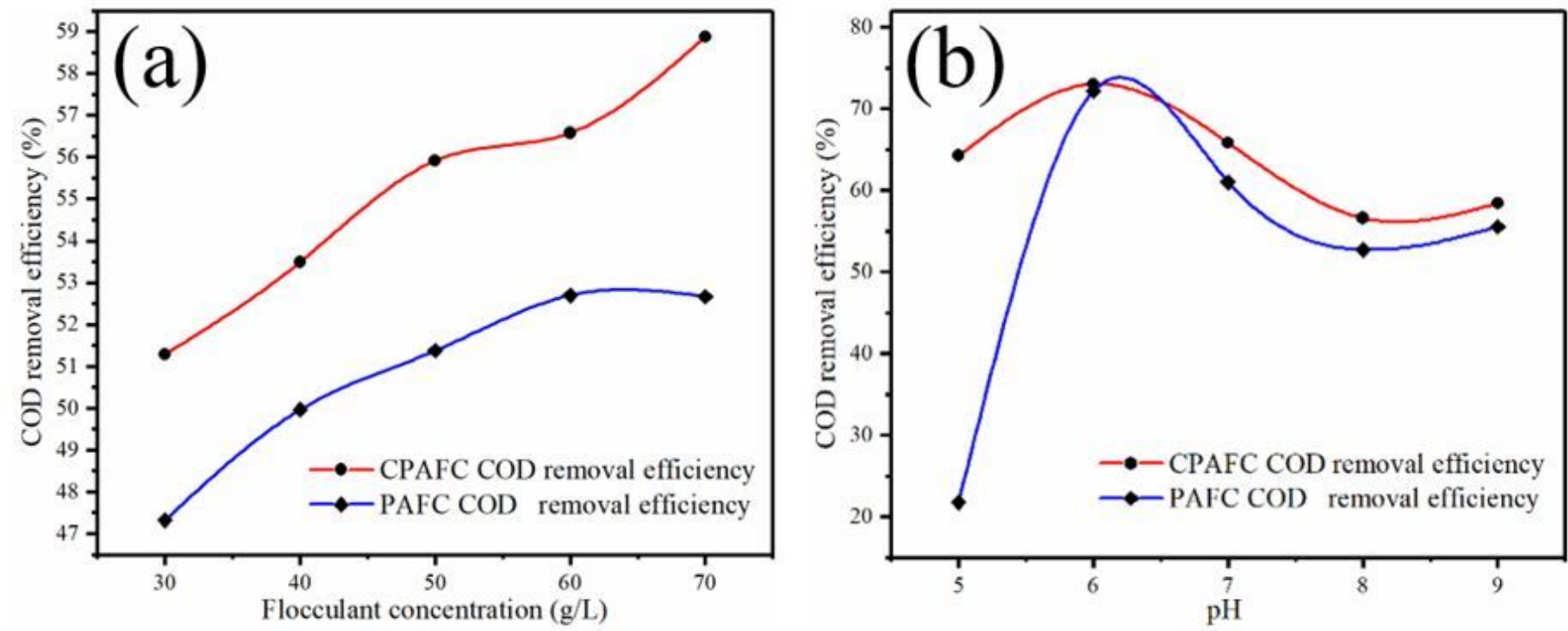

Figure 5 
(a) Influence of adding concentration $(\mathrm{pH}=8)$ and $(\mathrm{b})$ initial $\mathrm{pH}$ of solution (added concentration $=60 \mathrm{~g} / \mathrm{L}$ ) on the COD removal efficiency of landfill leachate.
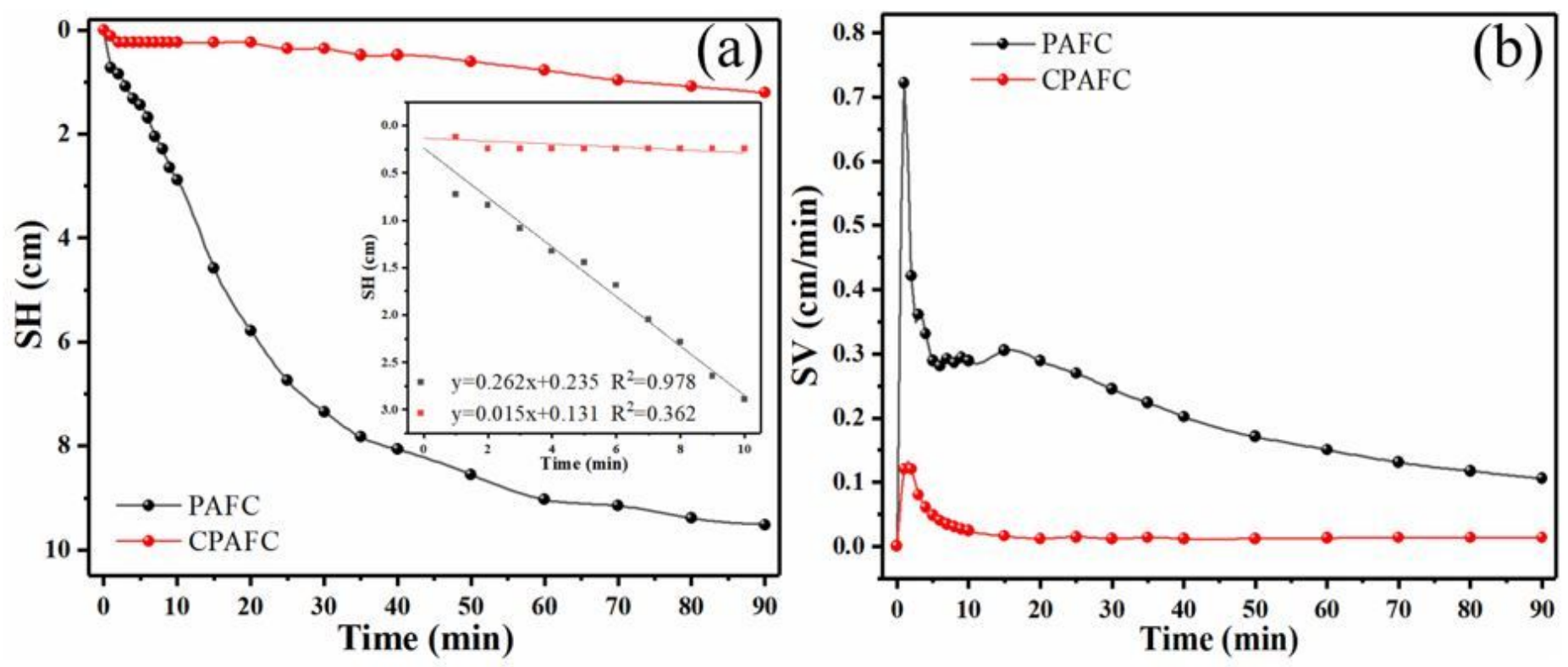

Figure 6

(a) SH curves (illustration: linear fitting during initial settlement phase) and (b) SV curves of flocculation at different settling times. 


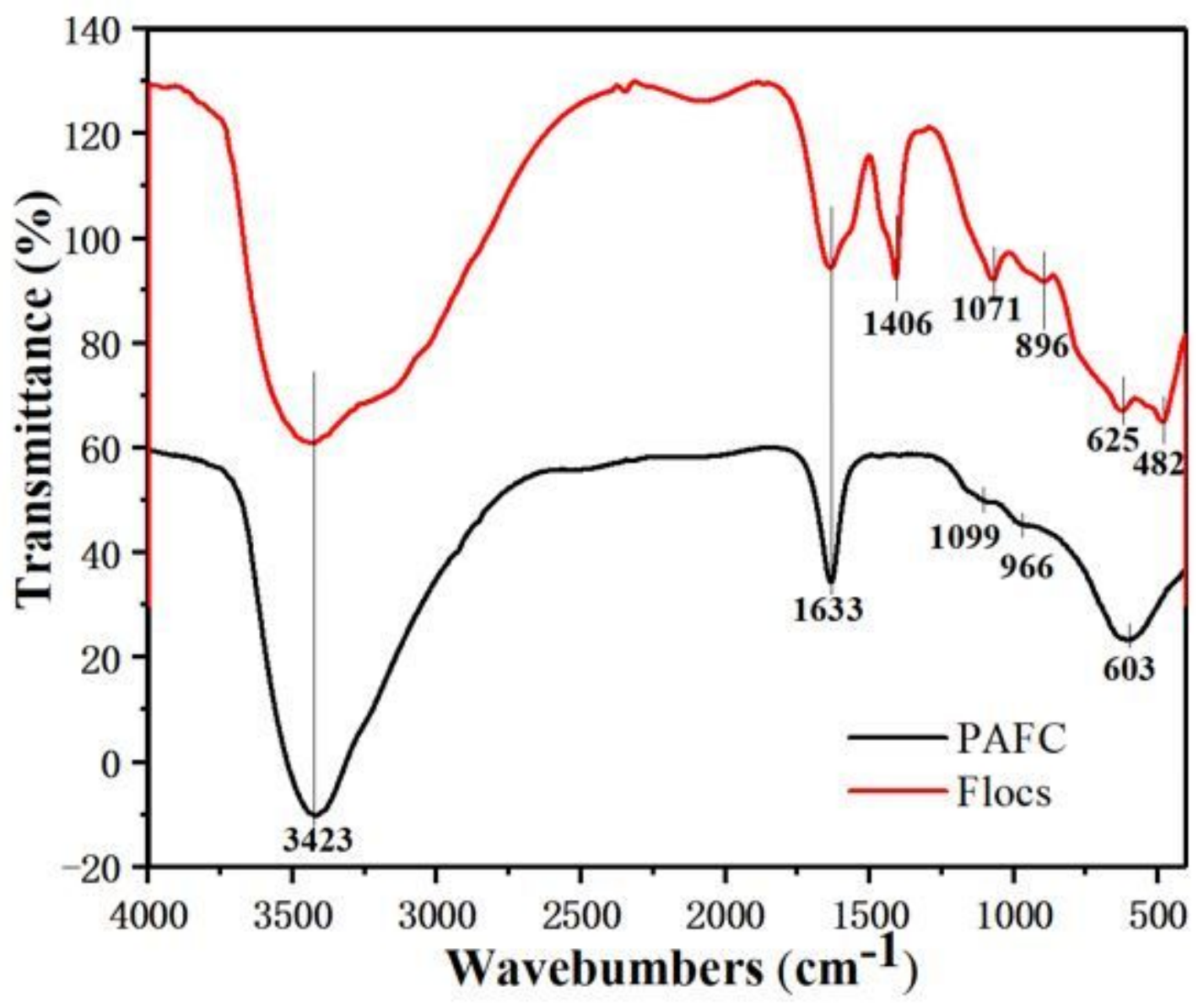

Figure 7

FTIR spectrum of the prepared PAFC and the flocs after PAFC treatment. 


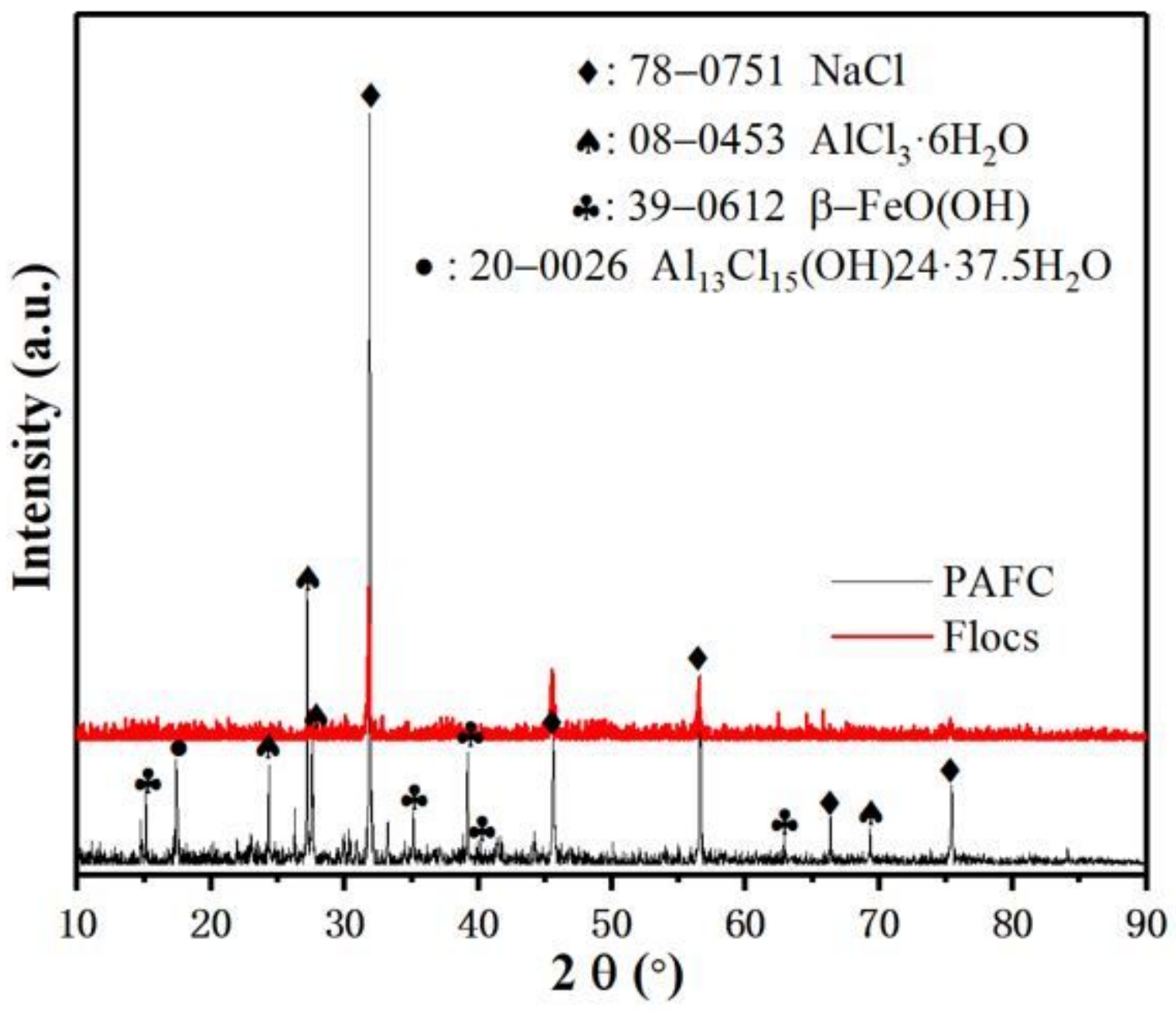

Figure 8

XRD pattern of the prepared PAFC and the flocs after PAFC treatment. 


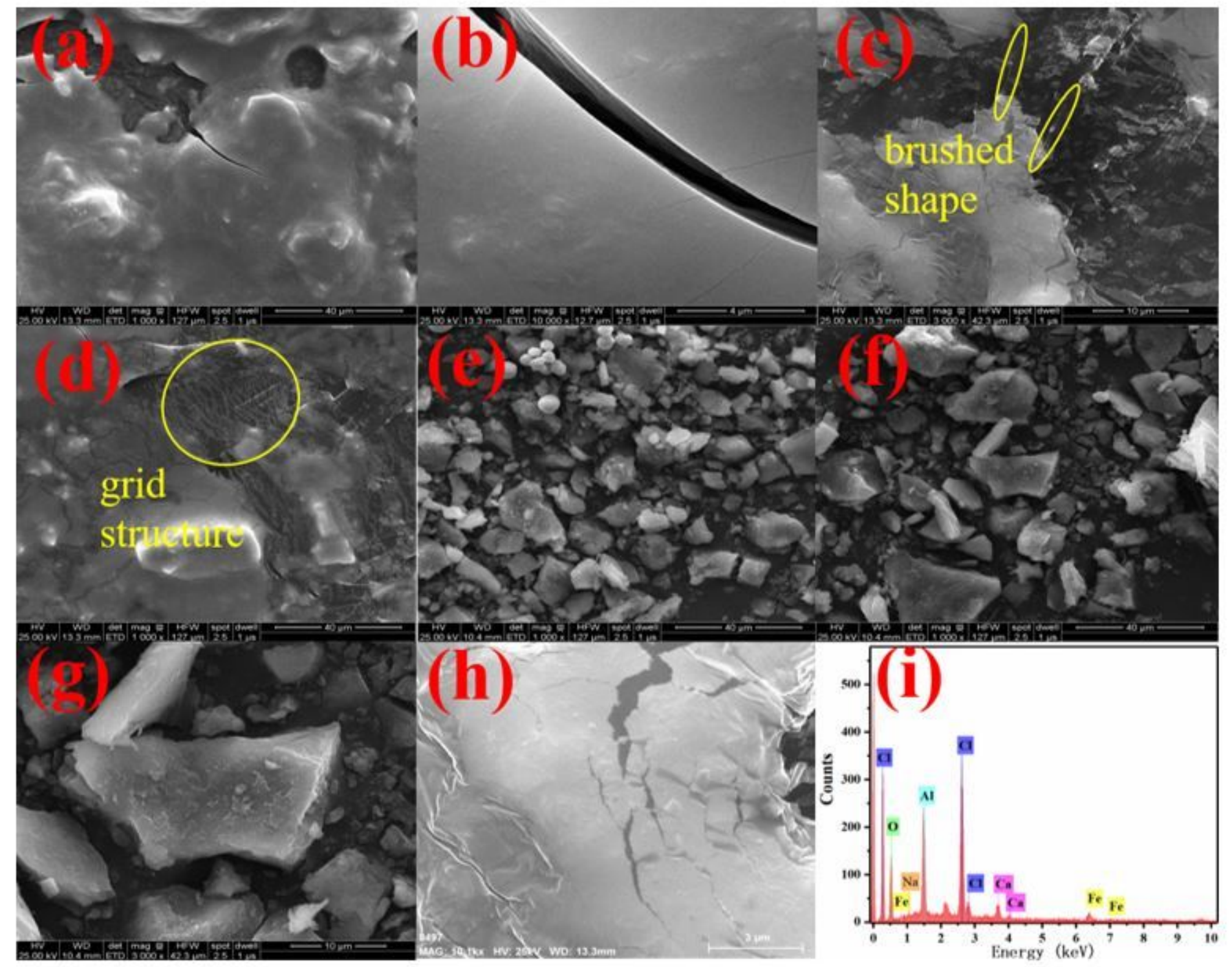

Figure 9

(a)-(d) PAFC and (e)-(g) PAFC treated flocs SEM pictures; (h) EDS scanning surface; (i) EDS of PAFC. 


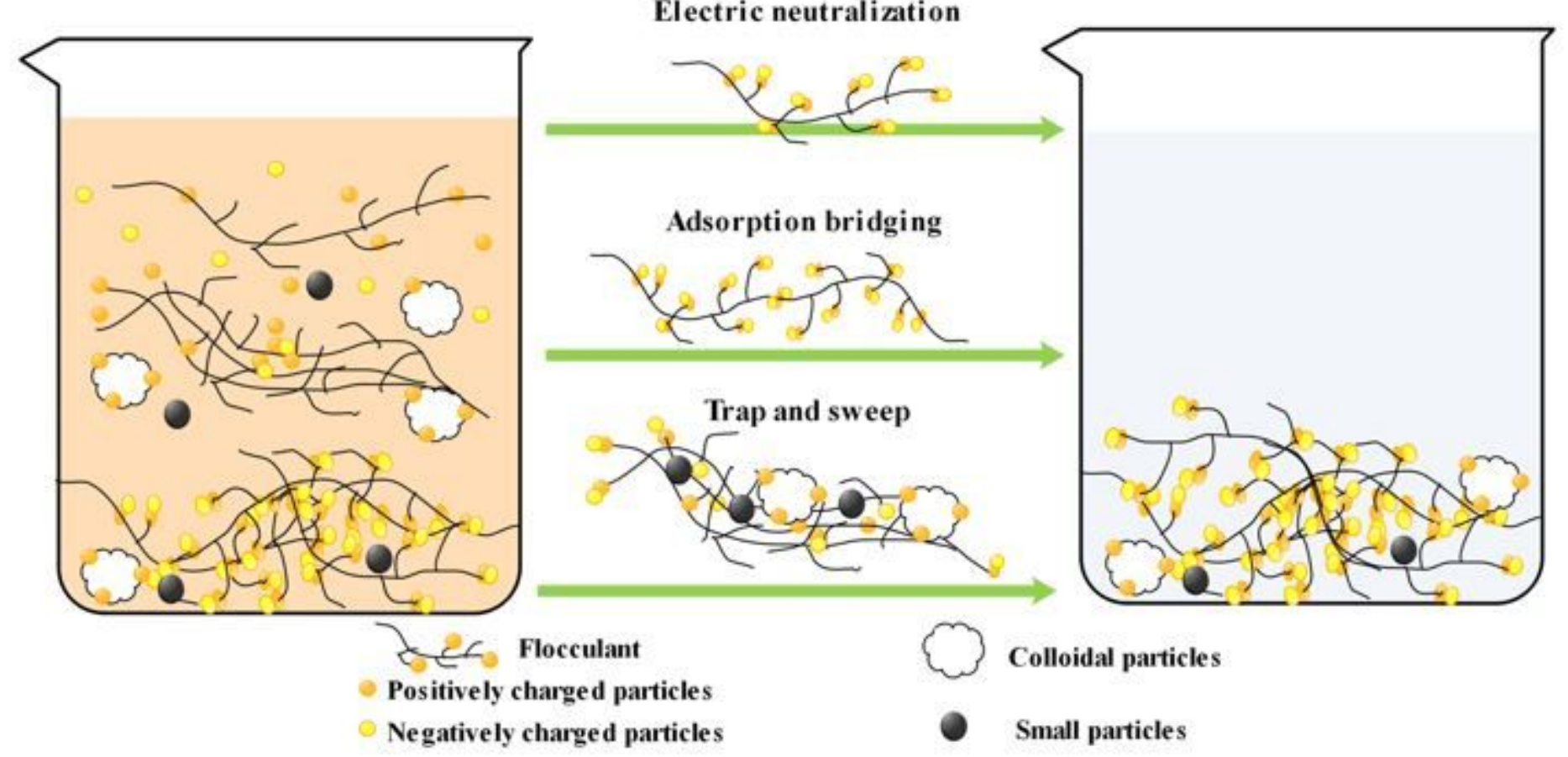

Figure 10

Possible schematic of PAFC flocculation.

\section{Supplementary Files}

This is a list of supplementary files associated with this preprint. Click to download.

- GraphicalAbstract.jpg 